\title{
O NOVO CONSTITUCIONALISMO LATINO AMERICANO: A PACHAMAMA E SUA RELAÇÃO COM O DESENVOLVIMENTO ECONÔMICO CAPITALISTA
}

\author{
THE NEW CONSTITUTIONALISM LATIN AMERICAN: THE PACHAMAMA \\ AND ITS RELATIONSHIP TO THE CAPITALIST ECONOMIC DEVELOPMENT
}

\author{
${ }^{1}$ Elisangela Prudencio dos Santos
}

\section{RESUMO}

O Novo Constitucionalismo levanta algumas temáticas importantes para a América Latina, contudo, as Constituintes de Equador [2008] e da Bolívia [2009] instituíram novas formas de pensar, que, inevitavelmente, romperam com as concepções clássicas. Propuseram um Estado plurinacional, um projeto decolonial e a instituição da Pachamama/Natureza como sujeito de direito. Essas mudanças paradigmáticas ocorreram com a insatisfação da sociedade andina com relação ao desenvolvimento clássico/capitalista e de sua proposta antropocentrista. As populações andinas por compreenderem a Pachamama/Natureza numa concepção biocêntrica não aceita de forma passiva os impactos negativos do extrativismo capitalista.

Palavras-chave: Novo constitucionalimo, Estado plurinacional, Decolonialidade, Pachamama, Modernidade, Desenvolvimento econômico

\begin{abstract}
The New Constitutionalism raises some important trends for Latin America, however, the Constituents of Ecuador [2008] and Bolivia [2009] introduced new ways of thinking, which inevitably broke with the classical conceptions. They proposed a plurinational and decolonialist project and the institution of Pachamama / Nature as a subject of rights. These paradigmatic changes occurred with the dissatisfaction of the Andean society with respect to the classic / capitalist development and its anthropocentric proposal. The Andean populations by understanding the Pachamama / Nature in a biocentric conception does not passively accept the negative impacts of the extractive capitalism.
\end{abstract}

Keywords: New constitutionalism, plurinational state, Decoloniality, Pachamama, Modernity, Economic development

\footnotetext{
${ }^{1}$ Mestranda em Direito na Universidade Católica de Pernambuco - UNICAP, Recife - PE (Brasil).

E-mail: elisangelaprudencio@ @otmail.com
} 


\section{INTRODUÇÃO}

O Novo Constitucionalismo Latino Americano vem, paulatinamente, apresentando aspectos relevantes para a teoria constitucional do direito. No seu terceiro ciclo, especificamente, nas Cartas do Equador [2008] e da Bolívia [2009] verifica-se a implementação de novas epistemologias distintas do Constitucionalismo clássico/liberal.

Essas Constituintes propuseram um Estado Plurinacional, o Pluralismo Jurídico e instituíram um ser "não humano" - Pachamama - como sujeito de direito. Assim, instituíram novas temáticas, que, suscitam, inevitavelmente, inúmeros questionamentos, inclusive, em face às concepções clássicas.

Além disso, apresentaram um projeto decolonial, com o fim de desconstruir, criticamente, a visão tradicional do colonialismo/modernidade e de analisar a subalternização cultural e epistêmica das culturas não europeias.

Por causa dessas inovações, esta pesquisa analisará as repercussões que esses novos institutos desencadearão na teoria do direito constitucional, especialmente, a da instituição da personalidade jurídica da Pachamama e de sua relação com o desenvolvimento econômico capitalista.

Para levantar essas informações, utilizou-se, tão somente, de dados bibliográficos

\section{O NOVO CONSTITUCIONALISMO LATINO AMERICANO: A PLURINACIONALIDADE DAS CARTAS DO EQUADOR E DA BOLÍVIA}

Pedro Brandão, criticamente, aborda na sua obra, que Dalmau e Viciano só visualizam no novo constitucionalismo um recorte progressista e democrático, apresentando fórmulas, que maximizam a participação cidadã e oferecem um suporte teórico para o controle dos atos estatais e dos representantes populares, em prol da efetiva intervenção cidadã, todavia, não realçam a concepção pluralista desse novo movimento, secundarizando as contribuições transformadoras do constitucionalismo equatoriano e boliviano para a teoria da constituição, notadamente, em relação à interculturalidade e plurinacionalidade [BRANDÃO, 2015, p. 35]. 
Contrariamente, a posição de Damau e Viciano, consigna Baldi, que as Constituintes do Equador e da Bolívia trazem novas concepções constitucionais que "rompem com a visão eurocentrada do mundo e admitem a inclusão de visões até então marginais na teoria constitucional, fruto também do forte protagonismo das comunidades indígenas" [BRANDÃO, 2015, p. 37].

Nessa mesma direção, Roberto Gargarella assinala que as Constituições que, efetivamente, rompem com a lógica elitista e individualista são as Cartas do Equador, principalmente, da Bolívia, internalizando as cosmovisões indígenas por meio da positivação dos direitos da Pachamama e rechaçando os "transplantes constitucionais" que não faziam parte da história cultural, política e jurídica de seus países [BRANDÃO, 2015, p. 51].

Observa Fajardo que no primeiro ciclo das reformas constitucionais do novo constitucionalismo latino americano foi inserido conceitos de diversidade cultural, de reconhecimento da configuração multicultural e multilingue da sociedade, de direito individual e coletivo, de identidade cultural e de alguns direitos indígenas, contudo, não houve, explicitamente, o reconhecimento do pluralismo jurídico [BALDI, 2015, pp. 38-39].

No segundo ciclo houve a implementação da ideia de pluralismo jurídico, desiderato que, no entender de Fajardo, rompeu com a identidade Estado-direito ou monismo jurídico, isto é, com a ideia de que somente é direito o sistema de normas produzido por órgãos soberanos de Estado - legislativo, judicial e executivo [BALDI,2015, pp. 38-39].

Já no terceiro ciclo surge o constitucionalismo plurinacional, instituído pelas Constituições do Equador [2008] e da Bolívia [2009], que romperam, explicitamente, com o modelo de Estado adotado pelo constitucionalismo liberal monista do século XIX e pelo constitucionalismo social integracionista do século $\mathrm{XX}$, chegando a questionar, inclusive, o colonialismo.

Urge consignar que o caráter plurinacional, previsto nas Constituintes andinas, é oriundo do reconhecimento que essas Cartas fazem das raízes milenares das populações indígenas originárias. Essa postura é um marco de um projeto descolonial, porque reconhece a jurisdição indígena e aspira um pluralismo jurídico igualitário, como bem assinala Raquel Fajardo 
haciendo un nuevo pacto de Estado, conforman un "Estado Plurinacional". En el marco de un proyecto descolonizador, reconocen la jurisdicción indígena y aspiran a un pluralismo jurídico igualitário [BALDI,

2015, 35].

Contudo, é pertinente ressaltar, a observação de Alberto Acosta quando afirma que a perspectiva plurinacional, prevista nas Cartas andinas, não tem por finalidade única reconhecer a diversidade de povos e de nacionalidades. Sua dimensão alcança também o desejo de incorporar diferentes posturas em relação à sociedade e à natureza [BALDI, 2015, p. 115].

\section{PROJETO DECOLONIAL: DESCOLONIALIDADE DO SABER E DO SER}

Para Mignolo, o objeto de estudo do projeto decolonial é a descolonização do saber e do ser, porque são problemas que "mantienen y reproduzen subjetividades y conocimientos y que son mantenidos por un tipo de economia que alimenta las instituciones, los argumentos y los consumidores". Por isso, para o autor, a proposta decolonial é uma opção e não um dogma para usar com força, como foi visto desde as cruzadas coloniais cristãs até o liberalismo colonial, desde o leninismo e stalinismo ao neoliberalismo. Trata-se de um pensamento que surge da experiência, nas fronteiras criadas pela expansão da Europa na diversidade [linguística, religiosa, social, subjetiva, econômica e política] do mundo.

Assim, para compreender a importância do projeto decolonial, nos moldes alicerçados nas Cartas andinas, urge entender, historicamente, o que significa a origem da modernidade e sua repercussão no mundo. Óbvio que esse artigo não se aprofundará na temática, mas lançará algumas ideias sobre esse fenômeno.

Dussel ao analisar sobre a origem da modernidade, aduz que a Europa nunca foi o centro da histórica mundial até os finais do século XVIII. Passará a ser o centro em consequência da revolução industrial. Mas graças a uma miragem, aos olhos obnubilados do eurocentrismo, toda a história mundial anterior lhe parece como tendo a Europa como centro, o que distorce o fenômeno da origem da modernidade [SANTOS e MENESES, 2015, p. 344].

O surgimento da modernidade decorreu com o processo de colonização, na América Latina. Por isso, a crítica afeta ao colonialismo, nas Constituintes do 
Equador e da Bolívia, se coaduna com a primeira crítica frontal contra a modernidade realizada por Bartolomé de Las Casas ${ }^{1}$, ao registrar, na sua obra, os sermões de Montesinos

Eu sou uma voz [...] no deserto desta ilha [...] todos estais em pecado mortal, $e$ nele viveis e morreis, pela crueldade e tirania que usais com essas inocentes vítimas. Não são homens os índios? Não têm almas racionais? Não sois obrigados a amá-los como vós mesmos? [... ] Como estais em tanta profundidade de sono tão letárgico adormecidos? [SANTOS e MENESES, 2015, p. 361].

Dussel noticia que Bartolomé de Las Casas, em 1550, enfrenta Ginés de Sepúlveda, no primeiro debate público filosófico e central da modernidade, para responder: Que direito tem a Europa de dominar colonialmente as Índias [Ocidentais]? Las Casas não concordava com o projeto de colonialismo, tampouco com a violência que esse projeto desencadeava, por isso, o refutava. Contudo, restou vencido pela prática colonial moderna das monarquias absolutas e do sistema capitalista como sistema-mundo. A modernidade nunca mais se perguntará, existencial e filosoficamente, por este direito à dominação da periferia até a atualidade. Este direito à dominação irá impor-se como a natureza das coisas e estará subjacente a toda a filosofia moderna. Ou seja, a filosofia moderna posterior ao século XVI irá desenvolver-se como pressuposto óbvio e oculto à não necessidade racional - porque é impossível e irracional - de fundamentar ética e politicamente a expansão europeia, o que não impede que se imponha essa dominação como o facto incontestável de se ter construído um sistema mundial assente na contínua exploração da periferia [SANTOS e MENESES, p. 368].

Por isso, Dussel registra tratar-se de um momento que a modernidade podia ter mudado o seu rumo. Não o fez e a rota fixou-se inflexível até ao século XXI. Era tal o assombro dos conquistadores de que tudo o que faziam era injustiça e falta moral contra os índios que não puderam crê-lo. Discutiu-se bastante, os dominicanos tinham os argumentos filosóficos, os colonos, os seus costumes tirânicos e injustos. No final, prevaleceram para sempre os costumes e foi sobre ele que se fundou a filosofia moderna europeia. A partir do século XVII nunca mais se irá discutir o direito dos europeus modernos [e, no século XX, o dos norte-americanos] em conquistar o planeta [SANTOS e MENESES, 2010, p. 362].

\footnotetext{
1 Dussel, no ensaio, Meditações anticartesianas sobre a origem do antidiscurso filosófico da modernidade, informa que Bartolomé é o primeiro crítico frontal da modernidade, dois decênios depois do primeiro momento do seu nascimento. Tudo teve início num Domingo de Novembro de 1511 quando Antón de Montesinos e Pedro de Córdova lançaram, na cidade de Santo Domingo, a primeira crítica contra o colonialismo inaugurado pela modernidade.
} 
Após analisar as colocações de Las Casas, Dussel referenda que, durante cinco séculos, toda a modernidade permanecerá nesse estado de consciência ético-política em situação 'letárgica', como 'adormecida', sem 'sensibilidade' perante a dor do mundo periférico do Sul.

Verifica-se, assim, que o surgimento da modernidade foi o momento da ausência de sensibilidade, porque o colonialismo, como bem assinala Quijano, é uma estrutura de dominação/exploração onde o controle da autoridade política, dos recursos de produção e do trabalho de uma população determinada domina outra de diferente identidade e cujas sedes centrais estão, além disso, localizadas noutra jurisdição territorial. Mas nem sempre, nem necessariamente, implica relações racistas de poder [SANTOS e MENESES, 2010, p. 85].

Dessa forma, para além de todas as dominações que o colonialismo propusera, observa Boaventura de Sousa Santos, tratar-se, ainda, de "uma dominação epistemológica, uma relação, extremamente, desigual de saberes que conduziu à supressão de muitas formas de saber próprias dos povos e nações colonizados, relegando outros saberes para um espaço de subalternidade" [SANTOS e MENESES,2010, p. 10].

Por isso, Quijano observa que a constituição da América Latina possibilitou o emergente poder capitalista tornar-se mundial e os seus centros hegemônicos se localizassem nas zonas situadas sobre o Atlântico, que depois se identificarão como Europa e como eixos centrais do seu novo padrão de dominação. Além disso, foi possível estabelecer a colonialidade. Em pouco tempo, com a América [Latina], o capitalismo tornase mundial, eurocentrado, e a colonialidade/modernidade instalam-se associadas como eixo constitutivos do seu específico padrão de poder, até hoje [SANTOS e MENESES, 2010, p.85].

Essa dupla intervenção foi de tal maneira profunda que descredibilizou e, sempre que necessário, suprimiu todas as práticas sociais do conhecimento que contrariassem os interesses que ela servia. Nisso, consistiu o epistemicídio, ou seja, a supressão dos conhecimentos locais perpetrada por um conhecimento alienígena [SANTOS, 1998, P. 208]. De fato, sob o pretexto da 'missão colonizadora', o projeto da colonização procurou homogeneizar o mundo, obliterando as diferenças culturais [MENESES, 2007]. Com isso, desperdiçou-se muita experiência social e reduziu-se a diversidade epistemológica, cultural e política do mundo. Na medida em que sobreviveram, essas experiências e essa diversidade foram submetidas à norma epistemológica dominante [SANTOS, 2010, p. 17]. 
Percebe-se, assim que o fim do colonialismo político, enquanto forma de dominação que envolve a negação de independência política de povos e/ou nações subjulgados, não significou o fim das relações sociais extremamente desiguais que ele tinha gerado, tanto relações entre Estados como relações entre classes e grupos sociais no interior do mesmo Estado [SANTOS e MENESES, 2010, p. 18].

Diante disso, percebe-se que o projeto decolonial proposto pelas Constituintes andinas suscitam uma leitura desconstrutiva crítica da visão tradicional do colonialismo/modernidade, do colonialismo/colonialidade e da análise da subalternização cultural e epistêmica das culturas não europeias, com o fim de implementar outras leituras que conviverão com as existentes, sem querer inserir-se como pensamento único, tampouco superior.

\section{A NOVA PERSONALIDADE DA PACHAMAMA: RUPTURA COM A CONCEPÇÃO ANTROPOCÊNTRICA}

A Pachamama é uma divindade protetora, cujo nome provém das línguas originárias e significa Terra, no sentido de mundo. Pachamama é a natureza. A ética derivada de sua concepção impõe a cooperação. Parte da premissa de que tudo que existe é um impulso que explica seu comportamento, inclusive, matéria inerte ou mineral e com maior razão o vegetal e o animal, de que resulta que todo o espaço cósmico é vivo e está movido por uma energia que conduz a relações de cooperação recíproca entre todos os integrantes da totalidade cósmica. Esta força é Pacha, que é 'todo o cosmo' e também 'todo o tempo'. Assim como Pacha é a totalidade, também é a possuidora do Espírito Superior Maior: "Pacha y su espíritu con uno solo aunque todos participamos de su espíritu" [ZAFFARONI, p. 119].

A Constituinte do Equador, expressamente, instituiu a Pacha Mama, como sujeito de direito, especificamente, no artigo abaixo transcrito

Artigo 71: La naturaleza o Pacha Mama, donde se reproduce y realiza la vida, tiene derecho a que se respete, integralmente, su existência y el mantenimiento y regenación de sus ciclos vitales, estructura, funciones y procesos evolutivos. Toda persona, comunidad, pueblo o nacionalidad podrá exigir a la autoridad pública el cumplimiento de los derechos de la naturaleza. Para aplicar e interpretar estos derechos se observaran los principios establecidos en la Constitución, en lo que proceda. El Estado incentivará a las personas naturales y jurídicas, y a los colectivos, para que protejan la naturaleza, y promoverá el respeto a todos los elementos que formam un ecosistema. 
Neste diapasão, a Carta Boliviana [2009] demonstra as mesmas aspirações que a Constituinte Equatoriana [2008], contudo, sob uma perspectiva tácita, mas não menos importante, conforme se vislumbra nos dispositivos abaixo transcritos

Preámbulo: [...] Un Estado basado en el respeto e igualdad entre todos, con principios de soberania, dignidad, complementariedad, solidaridad, armonía y equidad en la distribución y redistribución del producto social, donde predomina la búsqueda del Vivir Bien: con respeto a la pluralidade económica, social, jurídica, política y cultural de los habitantes de esta tierra: en convivencia colectiva con acceso al agua, trabajo, educación, salud y vivienda para todos. Cumpliendo el mandato de nuestros pueblos, con la fortaleza de nuestra Pachamama y gracias a Dios, refundamos Bolivia.

Artigo 33: Las personas tienen derecho a un medio ambiente saludable protegido y equilibrado. El ejercicio de este derecho debe permitir a los individuos y colectividades de las presentes y futuras generaciones, además de otros seres vivos, desarrollarse de manera normal e permanente.

O antecedente ao reconhecimento da Pachamama como sujeito de direito está nas lutas por territórios, água e soberania alimentar. Igualmente, nas lutas contra o extrativismo, os megaprojetos ou nas denúncias contra a manipulação do ecossistemas. Cada uma dessas lutas foi realizada com estratégias, que combinaram o teórico com o prático. Por isso houve resistência por meio de ações judiciais e por pressão nacional com âmbito internacional. Essas insurgências, colocaram a questão dos direitos da Natureza no centro de muitas discussões [MARTINEZ, 2011, 13].

Para Matías Ballone o reconhecimento de direitos coletivos, nas Constituições supramencionadas, alcança a proclamação dos direitos da Pachamama como continente dos demais direitos. Para o pesquisador, se instaura uma cosmovisão emergente que pretende reconstruir a harmonia e o equilíbrio da vida e que é a resposta das comunidades originárias dos povos andinos. Trata-se do paradigma do Buen Vivir $^{2}$ [ZAFFARONI, pp. $155-156]$.

\footnotetext{
2 Buen Vivir [Equador]; Vivir Bien [Bolívia]; Suma Qamanã [Aymara] e Sumak Kawsay [Quechua], termos que tem por fim designar o paradigma indígena de vida harmoniosa entre os humanos e a natureza [ZAFFARONI, p. 156].
} 
Alberto Costa aduz que nos Direitos Humanos, o centro está na pessoa. Trata-se de uma visão antropocêntrica. Nos Direitos da Natureza, o centro está na Natureza, que certamente inclui o ser humano. A Natureza vale por si mesma, independentemente da utilidade ou uso para o ser humano. Este aspecto é fundamental se aceitarmos que todos os seres vivos têm o mesmo valor ontológico, o que não implica que todos sejam idênticos. Isso é o que representa uma visão biocêntrica [COSTA, 2015].

Essas novas epistemologias, segundo Grijalva, rompem com a tradicional concepção judaico cristã de superioridade e divinização do ser humano [BALDI, 2015, p. 163]. Assim, em termos de direito, dentro da lógica liberal, estava permitido fazer qualquer atividade em relação a Natureza e por isso se estabeleceram regimes de apartheid social. A Natureza, assim, estava abaixo do categoria do direito a propriedade e os seres humanos abaixo da concepção de capacidade jurídica [BALDI, 2015, p. 163].

Zaffaroni observa que, após quinhentos anos de colonialismo, neocolonialismo, genocídio e dominação, não puderam barrar as culturas dos povos andinos ao culto da Terra e o ideal de convivência harmoniosa do Sumak Kawsay [ou Pachamama - grifo], que hoje removidas as capas que os oprimiam - retornam a superfície como mensagens ao mundo e em especial a espécie humana em risco de colapso e extinção [ZAFFARONI, 2011, p. 114].

\section{A PACHAMAMA E SUA RELAÇÃO COM O DESENVOLVIMENTO ECONÔMICO CAPITALISTA}

O antropólogo colombiano Arturo Escobar, assim como Tortosa, destaca o que representa a inclusão da Pachamama em uma Constituição:

É uma presença diferente que altera, fundamentalmente, o sentido de desenvolvimento e do Estado [...] porque semelhante pressuposto é, historicamente, impensável dentro de uma perspectiva moderna. Que este artigo apareça na Constituição Equatoriana é um evento político-epistêmico que revolve a história moderna e os políticos que a habitam - incluindo as esquerdas - porque desafia o liberalismo, o Estado e o Capital. Ambas ideias

- Os Direitos da Pacha Mama e o Buen Vivir - se baseiam em noções de vida em que todos os seres [humanos e não humanos] existem sempre na relação entre sujeitos, não entre sujeitos e objetos, e de nenhuma maneira individualmente [Acosta, 2015, p. 79]. 
Vê-se que a visão da Constituinte Equatoriana, que é similar a da Boliviana, prestigia a concepção biocêntrica do ser, rompendo com o antropocentrismo dos liberais. Assim, percebe-se que o conceito de natureza para os povos andinos é distinto dos povos ocidentais.

Um dos elementos de fundação da colonialidade/modernidade é o radical dualismo cartesiano, que separa a razão e a natureza. Daí, uma das ideias mais características do eurocentrismo, em qualquer de suas vertentes, é a exploração da natureza como algo que não requer justificativa alguma e que se expressa, cabalmente, na ética produtivista engendrada junto com a revolução industrial [Quijano, 2010, p.51].

Com amparo na premissa cartesiana, os grupos dominantes de homo sapiens na colonialidade global de poder, em especial desde a revolução industrial, tem levado a espécie a impor sua hegemonia exploratória sobre as demais espécies animais e uma conduta predatória sobre os demais elementos existentes no planeta. E sobre essa base, o capitalismo colonial/global pratica uma conduta, cada vez mais, feroz e predatória, que termina colocando em risco não somente a sobrevivência da espécie na terra, mas a continuidade e a reprodução das condições de vida na terra [QUIJANO,2010, p. 52].

Para Esperanza Martínez, os modernos visualizavam a natureza como fonte inesgotável de riquezas e depósito de desejos. Por isso, a natureza a serviço do capital tem convertido todos os seres viventes em matéria prima de diferentes processos industriais [2011, p. 7].

Ao contrário da concepção eurocêntrica da modernidade, as Constituintes do Equador e da Bolívia, neste século, propõem, segundo Boaventura de Sousa Santos, uma refundação de Estado, que deriva de um projeto de país consagrado pelo princípio do Buen Vivir, onde proclama os direitos da Pachamama, definindo um projeto de país que não se coaduna com a política desenvolvimentista do capitalismo

Cuando, por ejemplo, las Constituciones de Ecuador y Bolivia consagran el principio del buen vivir [Sumak Kawsay o Suma Qamaña] como paradigma normativo de la ordenación social y económica, o cuando la Constitución deEcuador consagra los derechos de la naturaleza entendida según la cosmovisión andina de la pachamama, definem que el proyecto de país debe orientarse por caminos muy distintos de los que conduzirán a las economías capitalistas, dependientes, extractivistas y agroexportadoras del presente [BALDI, 2015, p. 190].

Por isso, as Constituições do Equador e da Bolívia privilegiam um modelo econômico social solidário e soberano [León, 2009:65; Acosta, 2009a:20], alicerçado numa 
relação harmoniosa com a natureza que, na formulação de Gudynas [2009:39], deixa de ser um capital natural para converter-se num patrimônio natural.

A plurinacionalidade, instituída nas Cartas do Equador e da Bolívia, tem por fim enaltecer a cosmovisão indígena andina e ancestral do Buen Vivir, que, segundo Alberto Acosta, é uma oportunidade de construir outra sociedade sustentada em uma convivência cidadã, na diversidade e com harmonia com a Pachamama, a partir dos diversos valores culturais existentes no país e no mundo [2011, p. 9].

É cediço que as pretensões das constituintes andinas não serão, imediatamente, realizadas. Mas, suas propostas foram implementadas e é de grande relevância para a humanidade. Não devemos esquecer que são constituintes recentes. Contudo, Alberto Acosta observa que elas reproduzem, atualmente, mais aspirações, que resultados concretos

\begin{abstract}
Na gestão destes governos, considerados progressistas, mantém-se a importância dos setores extrativistas. Este extrativismo é novo pela combinação de velhas e novas características, mas não apresenta mudanças consideráveis no modo de acumulação primário exportador de origem colonial. $O$ destaque deste neoextrativismo é um maior envolvimento do Estado na gestão do setor exportador primário e na distribuição da renda de mineração ou petróleo. No entanto, este extrativismo do século XXI sustenta a integração internacional subordinada e funcional à globalização do capitalismo transnacional. Além disso, este extrativismo exacerbado faz pressão a favor de uma crescente fragmentação territorial e da consolidação de enclave extrativistas associados aos mercados globais. E tudo isso com crescentes impactos sociais e ambientais [ACOSTA, 2010, p. 211].
\end{abstract}

A observação de Acosta demonstra que a mudança proposta nas constituintes encontra-se longe de ser, efetivamente, implementadas, ante a força do capitalismo.

Contudo, não se deve esquecer o legado dessas Constituintes, que propõem refletir sobre a dominação dos povos e da natureza. Como bem assinala Galeano

\footnotetext{
Desde que a espada e a cruz desembarcaram em terras americanas, a Conquista europeia castigou a adoração da Natureza, que era pecado ou idolatria, com penas de açoite, forca e fogo. A comunhão com a Natureza e a gente, costume pagão, foi abolida em nome de Deus e depois em nome da civilização. Em toda a América e no mundo seguimos sofrendo as consequências desse divórcio obrigatório [ACOSTA, 2015, p. 105].
}

Ademais, adotar a definição pioneira de que a Natureza é um sujeito de direitos constitui uma resposta de vanguarda à atual crise civilizatória e como tal tem sido aceita por amplos segmentos da comunidade internacional conscientes de que é impossível continuar 
com o modelo de sociedade predatória, baseado na luta dos seres humanos contra a Natureza [ACOSTA, 2015, p. 127].

Assim, mesmo não existindo, efetivamente, a concretude das pretensões promulgadas nessas Constituintes, não se deve permitir, tampouco esquecer que suas inovações são esperanças para a humanidade e reflexões para a teoria geral do direito constitucional.

\section{CONCLUSÕES}

Nas reformas do Novo Constitucionalismo Latino Americano, especialmente, no seu terceiro ciclo, houve, efetivamente, a apresentação de novas epistemologias, que romperam com a visão eurocentrada de mundo, porque admitiram a inclusão de visões até então marginais na teoria constitucional tradicional.

Desse modo, as Constituintes do Equador [2008] e da Bolívia [2009] desestruturaram a lógica elitista e individualista, porque internalizaram as cosmovisões indígenas, quando da positivação dos direitos da Pachamama.

Assim, romperam com o modelo de Estado adotado pelo Constitucionalismo liberal monista do século XIX e pelo Constitucionalismo social integracionista do século $\mathrm{XX}$, chegando, inclusive, a questionar o colonialismo, através de sua proposta decolonial.

Essas Cartas reconheceram a jurisdição indígena e, ao mesmo tempo, propuseram uma política econômica desenvolvimentista biocêntrica distinta da concepção ocidental antropocêntrica.

Essas inovações ocorreram, porque as populações dessas regiões exigiam o direito de acesso aos territórios, a água e a soberania alimentar. Além disso, lutavam contra a política extrativista, os megaprojetos e a manipulação dos ecossistemas.

Essas insurgências, suscitaram reflexões sobre os direitos da Natureza, possibilitando sua instituição nas Constituintes andinas. Todavia, a Pachamama/Natureza prevista nas Constituintes andinas não tem o mesmo conceito e visão da que o ocidente compreende.

A modernidade, sob a ótica cartesiana, vislumbra a Natureza como um ser não humano, desprovido de direitos. Sua finalidade seria tão somente a de servir o humano. Ela estaria separada do humano e por esse subjugada. Diversamente, é o entendimento da cosmovisão indígena. Para os povos originários a Natureza/Pachamama é um ser de 
igual valor ao humano. Não existe entre eles nenhuma hierarquia. São seres que se interrelacionam e se complementam. Essa concepção propõe o humano inserido na Natureza, fazendo parte dela. Por isso, sua relação é de respeito e de cuidado.

Assim, por conceberem a Natureza de forma distinta, o desenvolvimento econômico da cosmovisão indígena é diferente do desenvolvimento capitalista/extrativista. Essa diferença, consequentemente, desencadeará tensões nessas regiões.

Desse modo, mesmo que as Constituintes andinas não consigam, concretamente, realizar suas aspirações, seu legado deve ser enaltecido e suas propostas devem ser exigidas por todos aqueles que acreditam num mundo melhor.

\section{REFERÊNCIAS}

ACOSTA, Alberto. Los derechos de la naturaleza: una lectura sobre el derecho a la existencia. In Acosta, Alberto; Martínez, Esperanza (Organizadores). La natureza con derechos: de la filosofia a la política, Quito, Abya-Yala, 2011.

ACOSTA, Alberto. Por uma declaração universal dos direitos da natureza:

reflexões para a ação, 2011. Disponível em: http://www.ihu.inisinos.br/noticias/41738por-uma-declaração-universal-dos-direitos-da-natureza-reflexões-para-a-acao.

ACOSTA, Alberto. O Buen Vivir: uma oportunidade de imaginar outro mundo, 2010, pp. 198-216.

ACOSTA, Alberto. Extractivismo y neoextractivismo: dos caras de la misma madición. In Más allá del desarrollo, Quito, Fundación Rosa Luxemburgo, 2011.

ACOSTA, Alberto. El buen vivir en el camino del post-desarrollo: una lectura desde la Constitución de Montecristi, Quito, Fundación Friedrich Ebert, 2010, pp. 537.

AGUSTÍN, GRIJALVA. Principales innovaciones en la Constitución de Ecuador de 2008. In Baldi, César Augusto (Coordenador). Aprender desde o sul: novas constitucionalidades, pluralismo jurídico e plurinacionalidade - aprendendo desde o sul, $1^{\text {a }}$ edição, Belo Horizonte, Forum, 2015, pp. 132-140.

ALCOREZA, Raúl Prada. Potencia social y poder en Bolivia: en defensa del proceso constituyente. In Baldi, César Augusto (Coordenador). Aprender desde o sul: novas constitucionalidades, pluralismo jurídico e plurinacionalidade - aprendendo desde o sul, $1^{\mathrm{a}}$ edição, Forum, Belo Horizonte, 2015, pp. 375-393.

BALDI, César Augusto. Direito constitucional e constitucionalismo interno, 2009. Disponível em: http://6ccr.pgr.mpf.br/documentosepublicacoes/docs_artigos/constitucionalismocolonial .pdf. Acesso 05/09/2015.

BALDI, César Augusto. Interculturalidade, direitos humanos e pluralismo jurídico, 2010. 
BALDI, César Augusto. Constitucionalismo latino-americano, 2011. Disponível em: http://files.campus.edublogs.org/blogs.udla.edu.ec/dist/0/59/files/2011/11/novoconstituc ionalismolatinoamericano-portugues-1 z5jvul.pdf, 2011. Acesso 11/09/2015.

BALDI, César Augusto. Novo constitucionalismo latino-americano: considerações conceituais e discussões epistemológicas. In Wolkmer, Antonio Carlos; Correas, Oscar (Organizadores). Crítica jurídica na américa latina, México, 2013, p. 90-207.

BRAGATO, Fernanda Frizzo; CASTILHO, Natalia Martibuzzi. A importância do póscolonialismo e dos estudos descoloniais na análise do novo constitucionalismo latino-americano. In: Val, Eduardo Manuel; Bello, Enzo (Organizadores). O pensamento pós e descolonial no novo constitucionalismo latino-americano, Editora da Universidade Caxias do Sul, Caxias do Sul, 2014. Disponível em: http://www.ucs.br/site/midia/arquivos/pensamentos_pos.pdf. 2014. Acesso: 06/08/2015.

BRANDÃO, Pedro. O novo constitucionalismo pluralista latino-americano. Rio de Janeiro, Lumen Juris, 2015, 262p.

CARBONELL, Miguel. Los retos del constitucionalismo en el siglo XXI. In Corte Constitucional de Ecuador para el período de transición. El nuevo constitucionalismo en américa latina. Disponível em: http://direito.ufg.br/up12/o/34272355-nuevoconstitucionalismo-en-america-latina.pdf?1352146324. Acesso 01/07/2015.

CLAVERO, Bartolomé. Bolivia: ley de la madre tierra contra os derechos de pueblos indigenas o legislación contra constitución, 2012, pp. 1-9. Disponível em: http://www.fobomade.org.bo/art-1772. Acesso 01/06/2015.

CLAVERO, Bartolomé; MAMANI, Carlos. Derechos de la madre tierra en medios no indígenas: america latina en movimiento, Quito, ano XXXVI, II época, n. 479, 2012 , p. $10-12$.

CLAVERO, Bartolomé. Estado plurinacional: aproximação a um novo paradigma constitucional americano. In Baldi, César Augusto (Coordenador). Aprender desde o sul: novas constitucionalidades, pluralismo jurídico e plurinacionalidade - aprendendo desde o sul, $1^{\text {a }}$ edição, Belo Horizonte, Forum, 2015, pp. 111-131.

DUSSEL, Enrique. O encobrimento do outro: 1492 a origem da modernidade, Petropólis, Vozes, 1993.

DUSSEL, Enrique. Meditações anticartesianas sobre a origem do antidiscurso filosófico da modernidade. In Santos, Boaventura de Sousa; Meneses, Maria Paula (Organizadores). Epistemologias do Sul. São Paulo, Cortez, 2010, pp. 341-391.

FANON, Frantz. Os condenados da terra. Tradução: José Laurênio de Melo, Civilização Brasileira, Rio de Janeiro, 1968.

FERNANDEZ, Raúl Llasag. Constitucionalismo plurinacional e intercultural de transición: Ecuador y Bolivia, v. 9, n. 1, Belo Horizonte, Meritum, 2014, pp. 295-319.

GARCÉS, Fernando. Estado-nación y Estado plurinacional: o cuando lo mismo no es igual. In Baldi, César Augusto (Coordenador). Aprender desde o sul: novas constitucionalidades, pluralismo jurídico e plurinacionalidade - aprendendo desde o sul, $1^{\mathrm{a}}$ edição, Belo Horizonte, Forum, 2015, pp. 427-445.

GUDYNAS, Eduardo. El mandato ecológico: derechos de la naturaleza y políticas ambiantales en la nueva constitución. In Acosta, Alberto; Martínez, Esperanza (Organizadores), Quito, Abya-Yala, 2009. 
GUDYNAS, Eduardo. et al. Diez tesis urgentes sobre el nuevo extractivismo: contextos y demandas bojo el progresismo sudamericano actual. Gudynas, Eduardo e et al. Extractivismo, Política y Sociedade, Quito, Fundación Rosa Luxemburg, 2009.

GUDYNAS, Eduardo. Si eres tan progresista, por qué destruyes la naturaleza? Neoextractivismo, isquierda y alternativas, Quito, Revista Ecuador Debate, n. 79, 2010.

GUDYNAS, Eduardo; ACOSTA, Alberto. El buen vivir o la disolución de la idea del progreso. Rojas, Mariano (Coordenador). La medición del progreso y del bienestar: propuestas desde américa latina, México, Foro Consultivo e Científico y Tecnológico de México, 2011.

GUDYNAS, Eduardo; ACOSTA, Alberto. La renovación de la crítica al desarrollo y el buen vivir como alternativa. Revista Utopía y Praxis Latinoamericana, Revista Internacional de Filosofía Iberoamericana y Teoria Social Centro de Estudos Sociológicos y Antropológicos, ano 16, n. 53, 2011.

GUDYNAS, Eduardo. Los derechos de la naturaleza en serio. In Acosta, Alberto; Martínez, Esperanza (Organizadores). La naturaleza con derechos: de la filosofía a la política, Quito, Abya-Yala, 2011.

GUDYNAS, Eduardo. Desarrollo, derechos de la naturaleza y buen vivir despues de Montecristi. In Centro de Investigaciones Ciudad y Observatorio de la Cooperación al Desarrollo. Debates sobre cooperação y modelos de desarrollo: perspectivas desde la sociedad civil en el Ecuador, Quito, Gabriela Weber, 2011, pp. 83-102.

GARAVITO, César Rodrígues. O impacto do novo constitucionalismo: os efeitos dos casos sobre os direitos sociais na américa latina. In Baldi, César Augusto (Coordenador). Aprender desde o sul: novas constitucionalidades, pluralismo jurídico e plurinacionalidade - aprendendo desde o sul, $1^{\text {a }}$ edição, Belo Horizonte, Forum, 2015, pp. 87-109.

GARGARELLA, Roberto. El nacimiento del constitucionalismo popular. In Roberto Gargarella (Organizador). Teoria crítica del derecho constitucional, Buenos Aires, Abeledo-Perrot, v. 1, 2008, pp. 249-265.

GARGARELLA, Roberto. Pensando sobre la reforma constitucional en américa latina. In: Garavito, César Rodrigues (Organizador). El derecho en america latina: un mapa para el pensamiento jurídico del siglo XXI. Buenos Aires, Siglo Veimtiuno, 2011, pp. 88-107.

GARGARELLA, Roberto. Constitucionalismo latino-americano: a necessidade prioritária de uma reforma política. In: Ribas, Luiz Otávio (Organizador). Constituinte exclusive: um outro sistema político é possível, São Paulo, Expressão Popular, 2014, pp. 9-19. Disponível em:

http://www.plebiscitoconstituinte.org.br/sites/default/files/material/livro\%20juridico\%2 0constituinte\%20exclusiva\%20202014.pdf. Acesso 10/06/2015.

GARGARELLA, Roberto. El nuevo constitucionalismo latinoamericano: promesas e interrogantes. In Baldi, César Augusto (Coordenador). Aprender desde o sul: novas constitucionalidades, pluralismo jurídico e plurinacionalidade - aprendendo desde o sul, $1^{\text {a }}$ edição, Belo Horizonte, Forum, 2015, pp. 58-85.

GROSFOGUEL, Ramón. Para descolonizar os estudos de economia política e os estudos pós-coloniais: transmodernidade, pensamento de fronteira e colonialidade global. In Santos, Boaventura de Sousa; Meneses, Maria Paula (Organizadores). Epistemologias do Sul, São Paulo, Cortez, 2010, pp. 455-488. 
GUSSOLI, Felipe Klein. A natureza como sujeito de direito na Constituição do Equador: considerações a partir do caso Vilacamba, Jornada de Iniciação Científica, na Universidade Federal do Paraná, 2014.

MAGALHÃES, José Luiz Quadros. Constituição x democracia: a alternativa plurinacional boliviana. In Baldi, César Augusto (Coordenador). Aprender desde o sul: novas constitucionalidades, pluralismo jurídico e plurinacionalidade - aprendendo desde o sul, $1^{\text {a }}$ edição, Belo Horizonte, Forum, 2015, pp. 360-372.

MARTÍNEZ DAMAU, Rubén. Asambleas constituyentes e nuevo constitucionalismo en américa latina. Tempo Exterior, n. 17. 2008, pp. 5-15.

MEDICI, Alejandro M. El nuevo constitucionalismo latinoamericano y el giro decolonial: Bolivia y Ecuador, Revista Derecho y Ciencias Sociales, La Plata, Argentina, n. 3, 2010, pp. 3-23. Disponível em: http://wwwceapedi.com.ar/imagenes/biblioteca/libros/191.pdf. Acesso 04/07/2015.

MIGNOLO, Walter. La idea de américa latina: la derecha la isquierda y la opción decolonial, ano I, n. 2, pp. 251-270, 2009.

MUÑOZ, Daniel Eduardo Flórez. Tres modelos explicativos de las tensiones entre constitucionalismo y democracia en américa latina. Munõz, Daniel Eduardo Flórez. Revista Jurídica Mario Alario D'Filippo, vol. v, n. 9, 2013, pp. 159-168.

PRADA, Raúl. Deconstruir el Estado y refundar la sociedad: socialismo comunitario y Estado plurinacional. In Lang, Mirian; Santillana, Alejandra (Organizadoras). Democracia, participación y socialismo: Bolivia, Equador y Venezuela. Quito, 2010, pp. 69-86. Disponível em: http://www.rosalux.org.ec/attachments/article/170/democraciaparticipación-y- socialismo-bolivia-ecuador-venezuela.pdf. Acesso: 25/05/2015.

QUIJANO, Aníbal. Colonialidad del poder, eurocentrismo y américa latina. In Lander, Edgardo (Organizador). La colonialidad del saber: eurocentrismo y ciencias sociales: perspectivas latinoamericanas, Buenos Aires, CLACSO, 2000, pp. 201-246.

QUIJANO, Aníbal. Colonialidade do poder e classificação social. In Santos, Boaventura de Sousa; Meneses, Maria Paula (Organizadores). Epistemologias do Sul. São Paulo, Cortez, 2010, pp. 84-126.

SANTAMARÍA, Ramiro Ávila. El neoconstitucionalismo transformador: el Estado y el derecho en la consittución de 2008, Quito, Abya-Yala, 2011.

SANTAMARÍA, Ramiro Ávila. El derecho da la naturaleza: fundamentos. In Alberto Acosta; Esperanza Martínez (Organizadores). La naturaleza con derechos: de la filosofía a la política, Quito, Abya-Yala, 2011.

SANTOS, Boaventura de Sousa. La refundación del estado e los falsos positivos. In Baldi, César Augusto (Coordenador). Aprender desde o sul: novas constitucionalidades, pluralismo jurídico e plurinacionalidade - aprendendo desde o sul, $1^{\mathrm{a}}$ edição, Belo Horizonte, Forum, 2015, pp. 179-211.

SANTOS, Boaventura de Sousa. Para além do pensamento abissal: das linhas globais a uma ecologia de saberes. In Santos, Boaventura de Sousa; Meneses, Maria Paula (Organizadores). Epistemologias do Sul. São Paulo, Cortez, 2010, pp. 31-66. 
SANTOS, Gustavo Ferreira. Poder constituinte e poder de reforma no novo constitucionalismo latino-americano: as lições que podemos tirar, Belo Horizonte, 2013, Revista Brasileira de Estudos Constitucionais, ano 7, n. 26, pp. 307-316.

SHIVA, Vandana. Democracia de la tierra y los derechos de la naturaleza. In Acosta, Alberto Acosta; Martínez, Esperanza (Organizadores). La naturaleza con derechos: de la filosofía a la política, Quito, Abya-Yala, 2011.

SIEDER, Rachel. Pueblos indígenas y derecho (s) en América Latina. In Garavito, César Rodrígues (Organizador). El derecho en América Latina: un mapa para el pensamento jurídico del siglo XXI, Buenos Aires, Siglo Veintiuno, 2011, pp. 303-322.

TORRES, Nelson Maldonado. A topologia do ser e a geopolítica do conhecimento: modernidade, império e colonialidade. In Santos, Boaventura de Sousa; Meneses, Maria Paula (Organizadores). Epistemologias do Sul. São Paulo, Cortez, 2010, pp. 398-438.

VAL, Eduardo Manuel; BELLO, Enzo. O pensamento pós e descolonial no novo constitucionalismo latino-americano. Val, Eduardo Manuel; Bello, Enzo (Organizadores). Caxias do Sul, Editora da Universidade de Caxias do Sul, 2014. Disponível em: http://www.ucs.br/site/midia/arquivos/pensamento_pos.pdf. Acesso

$10 / 06 / 2015$.

VARGAS, Idón Moisés Chivi. Os caminhos da descolonização na américa latina: os povos indígenas e o igualitarismo jurisdicional na Bolívia. In Verdum, Ricardo (Organizador). Povos indígenas: constituições e reformas políticas na américa latina. Instituto de Estudos Socioeconômicos, Brasília, 2009, pp. 151-166.

VARGAS, Idón Moisés Chivi. Constitucionalismo y descolonización: aportes al nuevo constitucionalismo latino americano. In Baldi, César Augusto (Coordenador). Aprender desde o sul: novas constitucionalidades, pluralismo jurídico e plurinacionalidade aprendendo desde o sul, $1^{\text {a }}$ edição, Belo Horizonte, Forum,

2015, pp. 215-224.

VICIANO PASTOR, Roberto; MARTÍNEZ DAMAU, Rubén. Presentación. Aspectos generales del nuevo constitucionalismo latinoamericano. In Corte Constitucional do Ecuador. El nuevo constitucionalismo en América Latina, Quito, 2010, pp. 9-44. Disponível em: http://www.direito.ufg.br/up/12/o/34272355-nuevo-constitucionalismo- enamerica-latina.pdf. Acesso: 23/07/2015.

VICIANO PASTOR, Roberto; MARTÍNEZ DAMAU, Rubén. Los procesos constituyentes latinoamericanos y el nuevo paradigma constitucional, Puebla, Revista del Instituto de Ciencias Jurídicas de Puebla A.C., n. 25, 2010, pp. 7-29.

VICIANO PASTOR, Roberto; MARTÍNEZ DAMAU, Rubén. Fundamentos teóricos y prácticos del nuevo constitucionalismo latinoamericano. Revista General de Derecho Público Comparado, n. 9, 2011, pp. 307.328.

VICIANO PASTOR, Roberto; MARTÍNEZ DAMAU, Rubén. et al. La naturaleza emancipadora de los procesos constituyentes democráticos. Avances y retrocesos. In Por una asamblea constituyente: una solución democrática a la crisis, Madri, Sequitor, 2012, pp. 13-28. 
VICIANO PASTOR, Roberto; MARTÍNEZ DAMAU, Rubén. La Constitución democrática, entre el neoconstitucionalismo y el nuevo constitucionalismo, 2013, pp. 63-82.

VICIANO PASTOR, Roberto; MARTÍNEZ DAMAU, Rubén. Se puede hablar de un nuevo constitucionalismo latinoamericano como corriente doctrinal sistematizada?

2011, p.1-23. Disponível em:

http://www.juridicas.unam.mx/wccl/ponencias/13/245.pdf. Acesso 20/07/2015.

RIBAS VIEIRA, José. O novo constitucionalismo latino-americano: paradigmas e contradições. Ribas Vieira, José. et al. Revista Quaestio Iuris, vol. 06, n. 2, 2013.

YRIGOYEN FAJARDO, Raquel Z. Pluralismo jurídico y jurisdición indígena en el horizonte del constitucionalismo pluralista. In Baldi, César Augusto (Coordenador). Aprender desde o sul: novas constitucionalidades, pluralismo jurídico e plurinacionalidade - aprendendo desde o sul, $1^{\text {a }}$ edição, Belo Horizonte, Forum, 2015, pp. 35-57.

YRIGOYEN FAJARDO, Raquel Z. EI horizonte del constitucionalismo pluralista: del multiculturalismo a la descolonización. In Garavito, César Roberto (Organizador). El derecho en América Latina: un mapa para el pensamiento jurídico del siglo

XXI, Buenos Aires, Siglo Veintiuno, 2011, pp. 139-184.

WALSH, Catherine. Interculturalidad crítica y pluralismo jurídico: reflexiones en torno a Brasil y Ecuador. In Baldi, César Augusto (Coordenador). Aprender desde o sul: novas constitucionalidades, pluralismo jurídico e plurinacionalidade - aprendendo desde o sul, $1^{\text {a }}$ edição, Belo Horizonte, Forum, 2015, pp. 343-356.

WALSH, Catherine. Interculturalidad, Estado, sociedade: luchas (des)coloniales de nuestra época, Quito, Abya-Yala, 2009.

WILHELMI, Marco Aparicio. Ciudadanías intensas: alcances de la refundacíon democrática en las constituciones de Ecuador y Bolivia. In Baldi, César Augusto (Coordenador). Aprender desde o sul: novas constitucionalidades, pluralismo jurídico e plurinacionalidade - aprendendo desde o sul, $1^{\text {a }}$ edição, Belo Horizonte, Forum, 2015, pp. 459-478.

WOLKMER, Antonio Carlos; MELO, Milena Peters. Constitucionalismo latinoamericano: tendências contemporâneas. In Wolkmer, Antonio Carlos; Melo, Milena Peters, Curitiba, Curitiba, 2013.

WOLKMER, Antonio Carlos; CORREAS, Oscar. Crítica jurídica na América Latina. In Wolkmer, Antonio Carlos Wolkmer; Correas, Oscar (Organizadores), Aguascalientes, CENEJUS, 2013, 1365 pp.

WOLKMER, Antonio Carlos; FAGUNDES, Lucas Machado. Para um novo paradigma de Estado plurinacional na América Latina, 2013, Revista NEJ, vol. 18, n. 2, 329-342.

TAPIA, Luis. Consideraciones sobre o estado plurinacional. In Baldi, César Augusto (Coordenador). Aprender desde o sul: novas constitucionalidades, pluralismo jurídico e plurinacionalidade - aprendendo desde o sul, $1^{\text {a }}$ edição, Belo Horizonte, Forum, 2015, pp. 481-501. 
UPRIMMY, Rodrigo. Las transformaciones constitucionales recientes en América Latina: tendencias y desafios. In Garavito, César Rodrigues (Organizador). El derecho en América Latina: un mapa para el pensamiento jurídico del siglo XXI, Buenos Aires, Siglo Veintiuno, 2011, pp. 109-138.

ZAFFARONI, Raúl Eugenio. La Pachamama y el humano, $1^{\text {a }}$ edição, Buenos Aires, Madres de Plaza de Mayo, 2011. 